Neurosurg Focus 19 (1):E1, 2005

\title{
Skull base surgery: past, present, and future trends
}

\author{
Joseph C. Maroon, M.D. \\ Department of Neurosurgery, University of Pittsburgh Medical Center, Pittsburgh, Pennsylvania
}

The author outlines the history of skull base surgery and describes the new paradigm emerging with increasing use of endoscopic microneurosurgery.

KEY WORDS • endoscopy • skull base • endonasal approach • history of neurosurgery

\begin{abstract}
There is nothing more difficult, more dangerous nor more least likely to succeed than to initiate a new order of things.
\end{abstract}

Niccolo Machiavelli (1469-1527)

\section{PIONEERS AND PRINCIPLES}

The roots of brain and skull base surgery extend deeply into the nineteenth century. Bold and creative physicians in every decade who challenged existing practices "to initiate a new order of things" often came under intense criticism and were even ostracized by their peers. The modern era of surgery required the discovery of anesthesia, antisepsis, and cortical localization, all of which initially were controversial; not unlike innovations at the present time. ${ }^{13}$

By 1831 all three basic anesthetic agents (ether, nitrous oxide gas, and chloroform) had been discovered, but medical applications for their pain-relieving properties were simply overlooked. A Connecticut dentist, Horace Wells, was booed and hissed from John C. Warren's medical class at Harvard when for some inexplicable reason his patient cried out in pain during an extraction while under the "influence" of nitrous oxide. Subsequently another dentist, William T. G. Morton, importuned Dr. Warren to use ether to remove a submaxillary vascular tumor in 1846. Although the surgery was successful, it still took several years before anesthesia was routinely used for leisurely operating without speed being the sine qua non of a good surgeon.

After watching many of his patients die of puerperal fever, Semmelweis (1818-1865) discovered that simple handwashing before and after each delivery markedly reduced this scourge of the birthing room. When he reported his results to the medical society of Vienna, he and his paper were greeted with virulent attacks. ${ }^{45}$ Ten years after his original discoveries, the profession hardly took notice and scientists as prestigious as Virchow still opposed his ideas. He ultimately was broken by the indifference and callousness of his superiors and colleagues and was committed to an asylum where he died in 1865 .

Abbreviation used in this paper: $\mathrm{CSF}=$ cerebrospinal fluid.
Finally, two Germans, Fritsch (1838-1927) and Hitzig (1838-1907) boldly exposed the brain of a dog on Fra Hitzig's drawing room table and used an electrical current to stimulate the exposed brain. They were roundly criticized for their experimentation despite the fact that their observations subsequently led to the modern era of brain localization.

Thus, with the discoveries of anesthesia, antisepsis, and cerebral localization the stage was finally set for the evolution of brain and skull base surgery. The earliest approaches to brain surgery were at the skull base. Francesco Durante (1845-1934) was the first to remove an olfactory groove meningioma from the skull base in a 35-year-old woman who presented with proptosis, loss of smell, and memory impairment. He induced chloroform anesthesia and applied antiseptic techniques together with cerebral localization, with a successful outcome documented 10 years later. ${ }^{13}$ In 1879 William Macewen (1849-1924) similarly successfully removed a brain tumor over the right eye in a 14-year-old patient by using a meticulous technique and what he referred to as antiseptic trephining. ${ }^{37}$ Macewen also introduced endotracheal intubation in place of tracheostomy in 1880 and modified the Lister technique by spraying carbolic acid over the wound.

Subsequent innovations in skull base surgery came relatively rapidly. Sir Victor Horsley (1857-1916) sectioned the posterior root of the trigeminal nerve for pain relief, Sir Charles Ballance (1856-1936) reported one of the earliest cases of acoustic tumor removal, and pioneers such as $\mathrm{Fe}$ dor Krause (1857-1937) from Germany, Thierry de Martel (1875-1940) from France, and others made major contributions to posterior fossa and skull base surgery. ${ }^{13,30}$

\section{SKULL BASE SURGERY}

\section{Transsphenoidal Approach}

In 1907 Schloffer (1868-1937) was the first to report successful removal of a pituitary tumor via a transnasal, transsphenoidal approach. ${ }^{44}$ His incision was external, along the left nasal labial fold, and the patient's nose was 
flapped to one side causing significant facial scarring. It was Oskar Hirsch (1877-1965), a Viennese otorhinolaryngologist, who in 1910 first described the endonasal, transseptal, transsphenoidal approach in which local anesthesia was used. ${ }^{17}$ Although Cushing did his first pituitary transsphenoidal operation in 1909 in a patient with acromegaly, he used Schloffer's technique. ${ }^{8} \mathrm{He}$ subsequently modified his operation to use Hirsch's endonasal and then subsequently his own sublabial incision with induction of general anesthesia instead of local infiltration with cocaine, and he used a head lamp for enhanced vision. He used this approach to perform operations in 231 patients with pituitary tumors, with a mortality rate of only $5.6 \%$ between the years 1910 and 1925. Because of the complications of CSF rhinorrhea, difficulty in controlling hemorrhage, and postoperative cerebral edema, he abandoned this approach and returned to the transcranial operation for pituitary tumors.

In 1923 Norman Dott (1897-1973), one of the founding fathers of neurosurgery in Great Britain, journeyed to Boston as a traveling fellow to study under Cushing. ${ }^{10} \mathrm{He}$ was impressed with the sublabial transsphenoidal approach to the pituitary and subsequently brought the technique back to Edinburgh. By 1956 he had no deaths in 80 consecutive transsphenoidal procedures.

In 1956 Girard Guiot (1912-1998) visited Dott, observed his meticulous technique and outcomes, and returned to Paris to reintroduce the endonasal approach to skeptical colleagues. ${ }^{15}$ Guiot introduced intraoperative radiofluoroscopy for improved localization and applied the transsphenoidal approach to craniopharyngiomas, clival chordomas, and parasellar lesions.

Another traveling fellow, Jules Hardy from Montreal, learned and closely evaluated the techniques of Guiot and then in 1967 first used the operating microscope in transsphenoidal surgery and designed his own set of microsurgical instruments. ${ }^{16}$ This occurred at the same time that a Turkish neurosurgeon from Zürich, Switzerland journeyed to Burlington, Vermont to learn microsurgical techniques in the laboratory of R. M. Peardon Donaghy. This neurosurgeon, Gazi Yaşargil, would subsequently be acclaimed the neurosurgeon of the century for his spectacular contributions to intracranial and skull base surgery.

With the incredible advances in intraoperative visualization offered by the operating microscope and localization with neuroimaging, innovative surgical approaches to the skull base proliferated. For the anterior fossa, the frontocranial, subfrontal-subcranial, transmaxillary-midface degloving, transfacial, and craniofacial approaches were either introduced or improved on. For the middle cranial fossa, the subtemporal, pterional, and orbitozygomatic approaches were introduced. For the posterior cranial fossa, the translabyrinthine, retrosigmoid, suboccipital, and extreme lateral approaches are used routinely. For the central skull base, the transoropalatal, transmaxillary, transfacial, and the transseptal-transsphenoidal approaches are now common. Dolenc, Fukushima, Samii, Sekhar, Al-Mefty, Jane Sr., Sen, and many more have made major contributions in this field.

\section{Extended Transsphenoidal Approach}

Several authors have modified and added to the extended transsphenoidal approach pioneered by Guiot and Har- dy. ${ }^{7,9,14,18,32-35,40,41,43,49}$ In their excellent review of the history and evolution of transsphenoidal surgery, Liu, et al. ${ }^{36}$ detail their own work as well as that of others in extending the transsphenoidal microscopic approach for lesions involving the planum sphenoidale to the upper portion of the clivus. As noted by Laws, et al., the extended transsphenoidal-skull base approach offers a variety of advantages, including that of removing bone instead of retracting brain to expose lesions, working along the axis of the tumor, devascularizing the blood supply from below, and not retracting or displacing critical structures such as the optic chiasm or optic nerves. ${ }^{38,42}$

\section{Endonasal Approach}

Technological advances have almost always preceded major improvements in skull base surgery. Fluoroscopy, intraoperative magnification, computerized tomography and magnetic resonance imaging, bipolar coagulation, digital angiography, and, more recently, frameless neuronavigation, Doppler ultrasonography, and artificial dural patches are just a few of these advances. ${ }^{12,19}$ Another major innovation was the introduction of the rod-lens endoscope to visualize cavities within the body. With endoscopes it became possible to introduce a point source of light with magnified images in proximity to a target through a small surgical corridor. Otolaryngologists capitalized early on this advance. Weigand, Messelklinger, Stammberger, and Kennedy pioneered the use of endoscopic nasal surgery to diagnose and treat lesions in and around the cranial sinuses. . $^{31,39,46-48,50}$

Taking advantage of the extensive experience with endoscopic sinus surgery among ear, nose, and throat specialists, the panoramic $360^{\circ}$ view provided by the endoscope, and the elimination of the rigid transsphenoidal retractor, Jho, a neurosurgeon, and Carrau, an ear, nose, and throat surgeon, began experimenting with the strictly endonasal transsphenoidal approach to pituitary tumors at the University of Pittsburgh.,21-24 They reported their experience in 50 patients in 1997. ${ }^{20}$ Their claims of faster hospital discharge, less operative trauma, and better patient satisfaction were challenged by their colleagues. ${ }^{22}$ Criticisms included the difficulty in controlling untoward hemorrhage when working through just one nostril, the lack of stereoscopic vision, inadequate instrumentation, and the persistent difficulty in controlling CSF leaks. Undaunted, other surgeons such as de Divitiis, Cappabianca, and others have continued to pioneer the endoscopic approach to skull base lesions. ${ }^{1-3,9}$

\section{Expanded Endonasal Approach}

Concurrent with Jho and Carrau's work on the endoscopic approach, Kassam and Snyderman, also at the University of Pittsburgh, proceeded on a parallel path beginning in $1998{ }^{5,6} \mathrm{In}$ a stepwise fashion they and others have used the adjuncts mentioned earlier, depending greatly on neuronavigation systems, and adopting a true team approach. In this way they have developed new instrumentation that allows surgical approaches, exposures, and tumor removal that were heretofore impossible. Expanding the unilateral endoscopic, endonasal, transsphenoidal route, they continue to perfect the bilateral endoscopic approach that allows exposure of tumors from the crista galli to C-2.11,25-29

This issue of Neurosurgical Focus represents a "how to do it" approach to endonasal surgery by some of the true 
pioneers in this new field. Patient selection, operative procedures, techniques for obtaining hemostasis, skull base repair, and specific nuances in tumor removal are all detailed.

As a student of the transsphenoidal approach for many years I have had the opportunity to observe the skull base operations performed by such giants as Guiot, Hardy, Yasargil, Wilson, Laws, and others. For the last 5 years I have observed and to a limited extent participated in the evolution of the expanded endonasal approach to lesions of the skull base.

Although it remains a work in progress, it is my opinion that the endoscopic approach represents a paradigm shift perhaps equivalent to the introduction of the microscope in approaching various skull base lesions. There remains much to be done in acquiring the skills, developing additional instrumentation, and improving on skull base repair, thus reducing CSF leaks and continuing to define optimal patient selection. The principles set forth in this volume of Neurosurgical Focus, however, underpin what I believe to be a firm foundation for this emerging field.

Clearly, detractors whose skepticism is understandable will remain, but the general principle we have seen in all of medicine pertains to any new idea or approach. Initially there is active resistance from peers, and after several years or longer and many presentations and papers, passive resistance develops. As others besides the innovators acquire the skill set, passive acceptance occurs, and finally active acceptance evolves as "we've always done it that way" becomes the norm. I believe that in the year 2005 we are in the passive resistance/passive acceptance stage preparatory to evolving into the active acceptance realm of this new field of collaborative endoscopic endonasal skull base surgery, which will indeed initiate a new order of things despite the danger and difficult nature of the innovation.

\section{References}

1. Cappabianca P, Alfieri A, de Devitiis E: Endoscopic endonasal transsphenoidal approach to the sella: towards functional endoscopic pituitary surgery (FEPS). Minim Invasive Neurosurg 41:66-73, 1998

2. Cappabianca P, Alfieri A, Thermes S, et al: Instruments for endoscopic endonasal transphenoidal surgery. Neurosurgery 45: 392-396, 1999

3. Cappabianca P, Frank E, Pasquini E, et al: Extended endoscopic endonasal transsphenoidal approaches to the suprasellar region, planum sphenoidale and clivus, in de Divitiis E, Cappabianca P (eds): Endoscopic Endonasal Transsphenoidal Surgery. New York: Springer-Verlag, 2003, pp 176-187

4. Carrau RL, Jho HD, Ko Y: Transnasal-transsphenoidal endoscopic surgery of the pituitary gland. Laryngoscope 106: 914-918, 1996

5. Carrau RL, Snyderman CH, Kassam AB: Endoscopic management of lesions of the median and middle skull base. Skull Base 11 (Suppl 1):6, 2001 (Abstract)

6. Carrau RL, Tosun F, Snyderman CH, et al: Endonasal endoscopic repair for CSF leak of the Sphenoid sinus. Skull Base 11 (Suppl 1):6, 2001 (Abstract)

7. Couldwell WT, Weiss MH: The transnasal transsphenoidal approach, in Apuzzo MLJ (ed): Surgery of the Third Ventricle, ed 2. Baltimore: Williams \& Wilkins, 1998, pp 553-574

8. Cushing H: Partial hypophysectomy for acromegaly. With remarks on the function of the hypophysis. Ann Surg 50: 1002-1017, 1909
9. de Divitiis E, Cappabianca P, Cavallo LM: Endoscopic transsphenoidal approach: adaptability of the procedure to different sellar lesions. Neurosurgery 51:699-707, 2002

10. Dott NM, Bailey P: A consideration of the hypophyseal adenomata. Br J Surg 13:314-366, 1925

11. Duvvuri U, Snyderman CH, Kassam AB: Trans-sphenoidal approach to petrous apex lesions: a case series. Skull Base 14 (Suppl 1):23-24, 2004 (Abstract)

12. Elias WJ, Chadduck JB, Alden TD, et al: Frameless stereotaxy for transsphenoidal surgery. Neurosurgery 45:271-277, 1999

13. Goodrich J: A millennium review of skull base surgery. Childs Nerv Sys 16:669-685, 2000

14. Griffith HB, Veerapen R: A direct transnasal approach to the sphenoid sinus. Technical note. J Neurosurg 66:140-142, 1987

15. Guiot G, Thibaut B: L'extirpation des adenomas hypophysaires par voie trans-sphenoidale. Neurochirurga 1:133-149, 1959

16. Hardy J: [Surgery of the pituitary gland, using the transspenoidal approach. Comparative study of 2 technical methods.] Union Med Canada 96:702-712, 1967 (Fr)

17. Hirsch O: Endonasal method of removal of hypophyseal tumors. With a report of two successful cases. JAMA 55: 772-774, 1910

18. Jane JA Jr, Dumont AS, Vance ML, et al: The transsphenoidal transtuberculum sellae approach for suprasellar meningiomas. Semin Neurosurg 14:211-218, 2003

19. Jane JA Jr, Thapar K, Alden TD, et al: Fluoroscopic frameless stereotaxy for transsphenoidal surgery. Neurosurgery 48: 1302-1308, 2001

20. Jho HD, Carrau RL: Endoscopic endonasal transsphenoidal surgery: experience with 50 patients. J Neurosurg 87:44-51, 1997

21. Jho HD, Carrau RL, Ko Y: Endoscopic pituitary surgery, in Reganchary SS, Wilkins RH (eds): Neurosurgical Operative Atlas. Park Ridge, IL: American Association of Neurological Surgeons, 1996, pp1-12

22. Jho JD, Carrau RL, Ko Y, et al: Endoscopic pituitary surgery: an early experience. Surg Neurol 47:213-222, 1997

23. Jho JD, Carrau RL, McLaughlin ML, et al: Endoscopic transsphenoidal resection of a large chordoma in the posterior fossa. Acta Neurochir 139:343-348, 1997

24. Jho HD, Ha HG: Endoscopic endonasal skull base surgery: Part 1-the midline anterior fossa skull base. Minim Invasive Neurosurg 47:1-8, 2004

25. Kassam A, Gardner P, Snyderman C, et al: Fully endoscopic endonasal resection of parasellar craniopharyngiomas: an early experience and review of the literature. Skull Base 14 (Suppl 1):21, 2004 (Abstract)

26. Kassam A, Pless M: Endoscopic endonasal transplanum approach to Chiasmatic lesions: a new paradigm in the surgical management of tumors compressing the optic chiasm, in North American Neuro-Ophthalmology Society, February 8-13, 2003. West Hartford, CT: NANOS, 2003, p. 140

27. Kassam A, Snyderman C, Carrau R: Expanded endonasal approach: an evolving paradigm to the ventral skull base. Skull Base 14 (Suppl 1):23, 2004 (Abstract)

28. Kassam A, Snyderman C, Carrau R: Expanded endonasal approach: transcribiform approach. Skull Base 14 (Suppl 1):10, 2004 (Abstract)

29. Kassam A, Snyderman C, Carrau R: Expanded endonasal approach: transplanum approach. Skull Base 14 (Suppl 1):10, 2004 (Abstract)

30. Keen WW, Spiller WG: On resection of the gasserian ganglion with a pathological report on seven ganglia. Am J Med Sci 116:503-532, 1898

31. Kennedy DW: Functional endoscopic sinus surgery. Technique. Arch Otolaryngol 111:643-649, 1985

32. Kim J, Choe I, Bak K, et al: Transsphenoidal supradiaphragmatic intradural approach: technique note. Minim Invasive Neurosurg 43:33-37, 2000

33. Kitano M, Taneda M: Extended transphenoidal approach with 
submucosal posterior ethmoidectomy for parasellar tumors. Technical note. J Neurosurg 94:999-1004, 2001

34. Kouri JG, Chen MY, Watson JC, et al: Resection of supraseller tumors by using a modified transsphenoidal approach. Report of four cases. J Neurosurg 92:1028-1035, 2000

35. Lalwani AK, Kaplan MJ, Gutin PH: The transsphenoethmoid approach to the sphenoid sinus and clivus. Neurosurgery 31: 1008-1014, 1992

36. Liu JK, Das K, Weis MH, et al: The history and evolution of transsphenoidal surgery. J Neurosurg 95:1083-1096, 2001

37. Macewen W: Intra-cranial lesions, illustrating some points in connexion with the localization of cerebral affections and the advantages of antiseptic trephining. Lancet II:581-582, 1881

38. McDonald TJ, Laws ER Jr: Historical aspects of the management of pituitary disorders with emphasis on transsphenoidal surgery, in Laws ER Jr, Randall RV, Kern EB, et al (eds): Management of Pituitary Adenomas and Related Lesions With Emphasis on Transsphenoidal Microsurgery. New York: Appleton-Century-Crofts, 1982, pp 1-13

39. Messerklinger W: Zur Endoskopietechnik des mittleren Nasenganges. Arch Otorhinolaryngol 221:297-305, 1978

40. Perneczky A, Fries G: Endoscope-assisted brain surgery: part 1 - evolution, basic concept and current technique. Neurosurgy 42:219-225, 1998

41. Raveh J, Turk JB, Ladrak K, et al: Extended anterior subcranial approach for skull base tumors: long-term results. J Neurosurg 82:1002-1010, 1995

42. Rodziewicz GS, Kelly RT, Kellman RM, et al: Transnasal endoscopic surgery of the pituitary gland: technical note. Neurosurgery 39:189-193, 1996

43. Sabit I, Schaefer SD, Couldwell WT: Extradural extranasal combined transmaxillary transsphenoidal approach to the cavernous sinus: a minimally invasive microsurgical model. Laryngoscope 110:286-291, 2000

44. Schloffer H: Zur frage der Operationen an der Hypophyse. Beitr Klin Chir 50:767-817, 1906 (Reference unverified)

45. Semmelweis IF: Die Aetiologie der Bergriff und die Prophylaxis des Kindbettfiebers. Hartlebens Verlags-Expedition, Pest Vienna Leipzig, 1861 (Reference unverified)

46. Stammberger H: Endoscopic endonasal surgery: Concepts in treatment of recurring rhinosinusitis. Part I. Anatomic and pathophysiologic considerations. Otolaryngol Head Neck Surg 94:143-147, 1986

47. Stammberger H: Endoscopic endonasal surgery-concepts in treatment of recurring rhinosinusitis. Part II. Surgical technique. Otolaryngol Head Neck Surg 94:147-156, 1986

48. Stammberger H, Posawetz W: Functional endoscopic sinus surgery. Concepts, indications and results of the Messerklinger technique. Eur Arch Otorhinolaryngol 247:63-76, 1990

49. Weiss MH: The transnasal transsphenoidal approach, in Apuzzo MJL (ed): Surgery of the Third Ventricle. Baltimore: Williams \& Wilkins, 1987, pp 476-494

50. Wigand ME: Transnasal ethmoidectomy under endoscopic control. Rhinology 19:7-15, 1981

Manuscript received June 2, 2005.

Accepted in final form June 20, 2005.

Address reprint requests to: Joseph C. Maroon, M.D., Department of Neurosurgery, University of Pittsburgh Medical Center, Pittsburgh, Pennsylvania 15213. email: maroonjc@upmc.edu. 